\title{
La Economía Social: su función económica y las políticas públicas de fomento
}

\author{
The Social Economy: its economic role and the public \\ policy promotion
}

\author{
AURELIO HERRERO-BLASCO
}

Universidad Politécnica de Valencia

Artículo recibido: 10 julio 2013

Solicitud de revisión: 09 octubre 2013

Artículo aceptado: 24 octubre 2013

Resumen

El propósito u objeto de este artículo es resaltar la importancia de la Economía Social y su papel fundamental a nivel de motor económico ya que presenta las siguientes ventajas : Distribuye de forma más igualitaria la renta y la riqueza, contribuye al desarrollo económico endógeno, incrementa la autonomía de los territorios, corrige los desequilibrios del mercado de trabajo, oferta más servicios de bienestar social, ayuda a la estabilidad económica y hace que el desarrollo económico sea sostenible. Asímismo, una vez justificada la importancia de la utilidad de la Economía Social, los poderes públicos deben reforzar e impulsar esas utilidades, mediante el fomento de políticas públicas que ayuden a impulsar estas características. Los objetivos que nos marcamos son: explicar en qué consiste esta función económica, describir los diferentes métodos de fomento que utilizan estas políticas públicas y explicar qué está haciendo la Unión Europea en cuanto al estímulo de la Economía Social. La metodología ha consistido en acudir a las distintas fuentes primarias y secundarias, reflejadas en la bibliografía utilizada, y considerar especialmente varios trabajos en los que nos hemos basado, ya que comportan análisis empíricos de bases de datos. Los principales resultados encontrados tanto a nivel nacional como a nivel europeo muestran que las Administraciones están empezando a tener en cuenta que la Economía Social es un sector estratégico frente a la crisis y el paro. Por ello, la conclusión más relevante es que, desde el ámbito académico, debemos continuar investigando cómo las políticas públicas pueden actuar como instrumento impulsor de la Economía Social.

Palabras clave:Economía Social, función económica, política pública, fomento.

\section{Abstract}

The purpose or object of this article is to highlight the importance of the social economy and its level role as economic engine has the following advantages: more equally distributes income and wealth, contributes to endogenous economic development, increases the autonomy of the territories, corrects imbalances in the labor market, offer social wel- 
fare services, economic stability helps and makes sustainable economic development. Also, once justified the importance of the utility of the Social Economy, governments should strengthen and boost those profits by encouraging public policies that help drive these features. The goals we set are: explain what this economic function, describe the different methods of promoting public policies that use these and explain what the eu is doing in terms of stimulating the Social Economy. The methodology has been to go to various primary and secondary sources, as reflected in the literature used, and especially consider several jobs that we have relied, and which involve empirical analysis databases. The main results both nationally and at European level show that the administrations are beginning to consider that the social economy is a strategic sector to the crisis and unemployment. Therefore, the most important conclusion is that from the academic must continue investigating how public policy can act as an instrument driver of Social Economy.

Keywords: Social Economy, economic role, public policy, promotion.

\section{INTRODUCCIÓN}

La función económica de la Economía Social, especialmente en lo que respecta a las cooperativas y sociedades laborales, que compiten en el mercado, tiene su fundamentación teórica, sobre todo, en la escuela europea representada por el Centro Internacional de Investigación e Información sobre la Economía Pública, Social y Cooperativa (CIRIEC). Sus máximos representantes son Jacques Defourny, catedrático del Centro de Economía Social (CEs) de la Facultad de Gestión de la Universidad de Lieja, y José Luis Monzón, catedrático de economía aplicada en la Facultad de Economía de la Universidad de Valencia, presidente de CIRIEC-España y presidente de honor de CIRIEC-Internacional, véase (Defournyy Monzón, 1992a; 1992b; Defourny y otros, 2009).

Particularmente, para la familia europea las cooperativas y sociedades laborales que compiten en el «sector mercado» son relevantes; no en cambio para la familia norteamericana, representada sobre todo por los catedráticos L.M. Salamon (Salamon y Anheir, 1992; 1993; 1996; Salamon, 1999) y B.A Weisbrod $(1975 ; 1977)$ representantes de la corriente Nonprofit, organizados entorno a la Universidad Johns Hopkins de Baltimore, en Maryland USA y la sociedad ISTR, The International SocietyforThird-Sector Research; dicha corriente niega la consideración de economía social a las cooperativas y sociedades laborales ya que reparten beneficios y, por tanto, sólo consideran economía social a las organizaciones nonprofit, es decir al sector de no-mercado de la Economía Social.

Así, en Europa, en 1999, el Comité Consultivo de la Comisión Europea de Cooperativas, Mutualidades, Asociaciones y Fundaciones (CMAF, 1999) 
estableció las siguientes notas para subrayar las características comunes del conjunto de organizaciones de la Economía Social que permiten diferenciarlas de las empresas capitalistas:

- Primacía de las personas y del objeto social sobre el capital: a excepción de las fundaciones, todas son empresas de personas.

- Adhesión voluntaria y abierta, y control democrático de sus miembros, de los usuarios y del interés general.

- Defensa y aplicación de los principios de solidaridad y responsabilidad.

- Autonomía de gestión e independencia de los poderes públicos.

- Aplicación del excedente al objeto social, mediante su reinversión o distribución, según los deseos de los miembros, para la creación de empleo, para realizar actividades, para crear nuevas empresas, retorno de capitales invertidos, actividades socioculturales, etc.

Está visión, la europea, hemos dicho que contrasta con la visión norteamericana «nonprofit» (Weisbrod, 1975; 1977) que considera Tercer Sector a aquellas entidades privadas que, en virtud de sus reglas constitutivas, no pueden distribuir beneficios a las personas que las controlan, teniendo que destinarse los mismos bien a la realización de sus objetivos, o bien a la ayuda de personas que no ejerzan ningún control sobre la organización.

De entre los enfoques NPO -Non-Profit Organizations-, el más divulgado es el de Salamon y Anheir (1992) y Anheir (2005) que establece cinco requisitos básicos para considerar a una organización como parte integrante del Tercer Sector:

- Organización formal, organized, i.e. intitucionalized to someextend, es decir, la organización debe estar estructurada, con objetivos claramente establecidos, identificación de su masa social y, normalmente, con un estatuto específico.

- Privada, private i.e. institutionally separate from government, es decir, institución separada del sector público, sin que éste pueda nombrar a sus administradores ni establecer su política general, aunque puede tener apoyo financiero público.

- No lucrativa, non-profitdistribuiting, i.e. no returning profits generate to the irowners, lo que significa que no puede distribuir beneficios a las personas que controlan la entidad. Si obtienen beneficios, éstos se destinan al desarrollo de sus fines o se reinvierten. 
Este último punto es el principal escollo y diferencia con la escuela europea, la cual distingue entre actividades económicas de mercado y de no mercado. Es en este marco en el que se desenvuelve esta comunicación, que continúa con el siguiente orden: en primer lugar, analizamos las funciones económicas de la Economía Social, las cuales van a justificar un tratamiento diferenciado de otras entidades de capital en lo referente a su promoción por parte de las políticas públicas. En segundo lugar, señalamos las distintas políticas públicas que se aplican para el fomento o apoyo de la Economía Social. En tercer lugar, describimos las acciones que ha emprendido la Unión Europea respecto al fomento de la Economía Social. Finalizamos con las conclusiones.

\section{LAS FUNCIONES DE LA ECONOMÍA SOCIAL EN EL SISTEMA ECONÓMICO}

La visión más extendida del sistema económico en los países desarrollados es la visión neoclásica-keynesiana, según esta visión existen dos sectores institucionales:

- Sector privado, identificado con el sector capitalista.Al sector privado se le suponen las ventajas de producción eficiente de bienes y servicios aunque se le reconocen una serie de deficiencias, que son los fallos del mercado.

- Sector público, que da soluciones a los fallos del mercado a través de la política económica.

Esta visión es muy simplista y, como es sabido, existen un gran número de entidades que no encajan en la anterior lógica neoclásica-keynesiana; así pues, estamos hablando de cooperativas, mutualidades, asociaciones, etc., Tercer Sector. En definitiva, tienen su propio espacio en el sistema económico, mejorando su funcionamiento, aliviando tensiones y problemas, generando nuevas oportunidades para la sociedad, portando determinados valores, que confieren al ser humano y a lo social, frente al mercado y al capital, nuevos cauces organizativos para formar otro modelo de desarrollo económico y estilo de vida de la Humanidad.

En este sentido, la Economía Social se ha revelado como un sector institucional particularmente eficaz en el desempeño de diversas funciones económicas como son las siguientes: 


\section{Cuadro 1}

Funciones económicas de la Economía Social

Distribución más igualitaria de renta y riqueza.

Desarrollo económico endógeno.

Autonomía de los territorios.

Corrección de desequilibrios del mercado de trabajo.

Oferta de servicios de bienestar social.

Estabilización económica.

Desarrollo sostenible.

Fuente: Chaves y otros, 1999.

\subsection{Distribución más igualitaria de la renta y la riqueza}

El sector de la Economía Social consta de mecanismos para distribuir más igualitariamente la renta y la riqueza, ya que:

- En las Cooperativas, sus reglas de distribución de beneficios priman a las personas, al uso de los servicios y al factor trabajo frente al capital.

- En las organizaciones altruistas, mediante sus servicios genuinos de redistribución, que son el voluntariado y las donaciones privadas.

\subsection{Desarrollo económico endógeno}

Las entidades de Economía Social tienen más capacidad para promover el desarrollo económico endógeno, especialmente donde no lo consiguen los otros dos sectores institucionales. Esto se debe a lo siguiente:

- Tienen mayor propensión a reinvertir los beneficios en el mismo territorio que los genera, promoviendo procesos de acumulación a nivel local.

- Por su capacidad para movilizar recursos existentes a nivel local. 
- Por su capacidad para crear y extender una cultura emprendedora y un tejido empresarial.

- Por su capacidad para engarzar la generación y/o ampliación de actividad económica con las necesidades locales, por ejemplo los servicios de proximidad y/o con el tejido productivo local.

- Por su capacidad para mantener actividades económicas con riesgo de desaparición por falta de rentabilidad, por ejemplo los artesanos, o por la fuerte competencia, las industrias tradicionales.

Todo esto en la práctica sirve para activar procesos de desarrollo endógeno en zonas rurales, para reactivar espacios urbanos degradados, y para reactivar zonas industriales en declive, aliviando con ello importantes desequilibrios territoriales.

\subsection{Autonomía de los territorios}

Las decisiones en este proceso económico se van a quedar en la sociedad civil autóctona, frente a los propietarios del capital globalizado que suele ser foráneo, esto se debe al modo de control y de toma de decisiones en las entidades de Economía Social, basado en el principio democrático y la participación ciudadana.Esta autonomía cobra especial importancia en la actualidad, un tiempo marcado por la globalización económica y la vulnerabilidad de los territorios.

\subsection{Corrección de los desequilibrios del mercado de trabajo}

La Economía Social corrige los tres principales desequilibrios del mercado:

- El paro,

- La inestabilidad en el empleo

- La inempleabilidad y exclusión sociolaboral de los parados.

Tradicionalmente, en España, han sido las Cooperativas de Trabajo Asociado (Ста) y las Sociedades Laborales (SLab) las que han desarrollado un papel más activo en este ámbito mostrando un «carácter anticíclico». 
De manera más reciente adquieren papel preponderante las nuevas entidades de Economía Social, como son las cooperativas sociales y otras entidades voluntarias que se sitúan en los llamados «nuevos yacimientos de empleo", como son servicios sociales y culturales. Estas organizaciones están revelando una gran capacidad creativa en el mercado de trabajo y van desarrollando nuevas concepciones del empleo, desde el trabajo voluntario por horas, hasta nuevas profesiones que de ellos surgen y se regulan a través de nuevos convenios colectivos.

Respecto a la estabilidad del empleo, las empresas de trabajo asociado han mostrado mayor capacidad relativa que las empresas capitalistas tradicionales, además de propiciar colaboraciones de innovación institucional importantes, como es el caso de Mondragón Corporación Cooperativa -MCC- en el País Vasco o Grup Empresarial Cooperatiu Valencià -GECV- en la Comunidad Valenciana.

Tenemos que destacar también que en las cooperativas el empleo es, además de más estable a nivel relativo, objeto de políticas de reducción de la jornada laboral o redistribución de ésta con mayor facilidad que en el sector capitalista.

Otro punto destacable es la capacidad de las empresas de Economía Social para, especialmente las llamadas empresas de inserción, integrar en el mercado de trabajo a aquellos colectivos con especiales dificultades de empleabilidad, un ejemplo de ello son las personas con minusvalías físicas o psíquicas o las personas con "minusvalías sociales», es decir, aquellos que han sido excluidas del mercado de trabajo durante largos períodos o que han seguido trayectorias laborales y sociales degenerativas en situaciones de marginación y pobreza.

\subsection{Oferta de servicios de bienestar social}

Las entidades de Economía Social presentan, en relación con el sector capitalista, ventajas comparativas de eficiencia en la asignación y producción de importantes grupos de servicios directamente ligados a las necesidades de la Sociedad. Se trata de servicios que están experimentando una fuerte expansión en los últimos lustros y que van a continuar creciendo en el futuro, como son: servicios de atención a las personas mayores, a las personas disminuidas o de cuidado de la infancia, servicios educativos, sanitarios, socioculturales, atención a refugiados y a otros colectivos desfavorecidos. 
El fallo asignativo del sector capitalista proviene, en unos casos, de la existencia de situaciones de información asimétrica entre oferentes y demandantes, lo cual le da al oferente capitalista el incentivo de explotar la ventaja informativa y que se traduce en un empeoramiento del nivel y calidad del servicio ofrecido; por el contrario, el incentivo citado desaparece en las entidades de Economía Social al existir identidad entre oferente y demandante, y al no distribuirse los beneficios, en el caso de una organización no lucrativa.

En otras ocasiones, el fallo asignativo del sector capitalista se produce por tratarse de demandas no solventes con escasa capacidad económica, lo que desincentiva al oferente capitalista al no poder maximizar sus beneficios.

Son, en definitiva, las entidades de Economía Social las que tienen la capacidad de dar servicio a sus socios o a la colectividad, sin ánimo de lucro, y pueden movilizar al voluntariado y motivar a los posibles donantes, de esta manera están en condiciones de soslayar estos fallos de mercado que hemos nombrado anteriormente, información asimétrica y demandas no solventes.

\subsection{Estabilización económica}

Las formas empresariales de Economía Social contribuyen a alcanzar un desarrollo económico sostenido y equilibrado, compatible con la seguridad económica de empresa y empleos. Como señala (Weitzman, 1987), la economía de la participación, en este caso las empresas son propiedad de los trabajadores, hace que disminuyan los incentivos para cerrar las empresas y despedir a los trabajadores en contextos de crisis económica o recesión del ciclo económico.

Otro método utilizado para lograr estabilidad económica es la transformación o reactivación de empresas tradicionales en situación de crisis en empresas propiedad de los trabajadores.

\subsection{Desarrollo sostenible}

La Economía Social está a favor de fomentar un estilo de vida y de desarrollo de la sociedad respetuoso con el ser humano y con el medio ambiente, de tal manera que en nuestro mundo desarrollado seamos capaces de 
reproducir los ecosistemas naturales, siendo conscientes de que esto no se conseguirá si no se apuesta por el cambio cultural, por el cambio de valores y por la educación.Estas aportaciones se han visto corroboradas a nivel científico por varios informes:

- El informe del Parlamento Europeo: Parlement, Comission de l'emploi et des affaires sociales. Rapport sur un modèle social européen pour l'avenir, año 2006, en el que se reconoce explícitamente a la Economía Social como el tercer pilar del modelo social europeo (Chaves y Monzón, 2008).

- El informe del Secretariado de Naciones Unidas: Las cooperativas en el desarrollo social (Naciones Unidas, 2007), en el cual se reconoce la contribución de las cooperativas a la promoción del pleno empleo y productivo, y su capacidad para luchar contra la pobreza, y se promueve el desarrollo social. Dicho informe afirma que :

Las Cooperativas facilitan el progreso económico y social de sus miembros mediante iniciativas de autoayuda y la asistencia en la lucha contra la pobreza. Los beneficios y el empleo generados por las Cooperativas permiten que sus miembros alcancen la seguridad económica e impiden que millones caigan en la pobreza.Al ayudar a sostener las oportunidades de ingreso y de e empleo, especialmente en las zonas remotas donde las iniciativas del sector público y otras del sector privado tienden a ser débiles o a no existir, las Cooperativas contribuyen a generar medios de vida sostenibles y a fomentar el desarrollo general de las comunidades locales donde funcionan» (Naciones Unidas, 2007:4).

- La Recomendación sobre la promoción de las cooperativas de la Organización Internacional del Trabajo, año 2002, reconoce la importancia de las cooperativas para crear empleo, para promover la participación de toda la población en el desarrollo económico y social, y para facilitar una distribución más equitativa de los beneficios de la globalización.

En definitiva, las cooperativas y el resto de la Economía Social son un mecanismo corrector de las deficiencias de los dos sectores tradicionales: el público y el privado capitalista. Ambos generan valor añadido social, son una herramienta fundamental para la promoción del desarrollo local, y constituyen un vector hacia un modelo de desarrollo social y económico más equilibrado. Por todo esto, la Economía Social puede ser un instrumento muy útil para solucionar la desigualdad y la pobreza y resulta clave para los programas de cooperación al desarrollo. 


\section{FORMAS DE APOYO O INCENTIVO A LAS ENTIDADES DE LA ECONOMÍA SOCIAL}

Existe un amplio espectro de medidas de fomento o incentivo a las empresas desde la administración, son las políticas públicas.

Estas medidas, que han sistematizado Chaves y Monzón (2003) y Chaves (2012), sugieren:

- Medidas institucionales dirigidas a eliminar obstáculos jurídicos al desarrollo de la Economía Social, como:

- La simplificación de los trámites administrativos para la creación de entidades de la Economía Social. La revisión de la normativa, a fin de suprimir las limitaciones de las entidades de la Economía Social, de forma que éstas puedan operar en cualquier actividad económica sin trabas injustificadas.

- La revisión de la Ley de Sociedades Laborales. La revisión de la normativa de desarrollo de la Ley General de Subvenciones para las entidades de acción social.

- Medidas de carácter cognitivo dirigidas a difundir, formar, investigar e innovar en este campo, como son:

- Promover los principios y valores de la Economía Social, promoviendo la formación y readaptación profesional en el ámbito de las entidades de la Economía Social.

- Introducir referencias a la Economía Social en los planes de estudio de las diferentes etapas educativas, facilitando el acceso a los procesos de innovación tecnológica y organizativa a los emprendedores de las entidades de Economía Social.

- Medidas institucionales dirigidas a establecer un órgano público de fomento de la Economía Social, que el Ministerio de Trabajo, junto con el Consejo de Fomento de la Economía Social, y las entidades representativas de la Economía Social de ámbito estatal, así como los expertos los que la impulsen.

- Medidas institucionales de inclusión explícita de la Economía Social en diversas políticas sectoriales, en las políticas activas de empleo, 
especialmente en aquellas a favor de los sectores más afectados por el desempleo: mujeres, jóvenes y parados de larga duración.

- En las políticas de desarrollo rural, de servicios sociales a personas dependientes y de integración social. La integración de las empresas de la Economía Social en las estrategias para la mejora de la productividad y de la competitividad empresarial.

\section{Cuadro 2}

Tipos de políticas de fomento de las cooperativas

1. Políticas soft. Políticas dirigidas a crear un entorno favorable a las empresas

Medidas institucionales

- Dirigidas a la forma jurídica en tanto que actor privado.

- De reconocimiento de la capacidad de operar de las cooperativas en todo sector de actividad económica, eliminando los obstáculos si los hubiere.

- De reconocimiento de las cooperativas como actor político e interlocutor en la elaboración y en la ejecución de políticas públicas.

- De impulso de organismos públicos de fomento de las cooperativas.

Medidas de carácter cognitivo

- De difusión y conocimiento de las cooperativas por la sociedad.

- De fomento de la formación en materia de cooperativas.

- De fomento de la investigación sobre cooperativismo.

\section{Políticas hard. Políticas económicas de fomento empresarial}

Medidas de oferta, dirigidas a mejorar la competitividad de las empresas cooperativas

- Medidas presupuestarias, fiscales y de apoyo financiero; medidas de apoyo técnico, formativo, etc. Se distinguen atendiendo al ciclo de vida de la empresa, según sea la fase de creación o de desarrollo empresarial y, a la función empresarial a fortalecer: financiación, consultoría/ asesoramiento, formación, empleo y gestión de recursos humanos, cooperación y redes I+D e innovación, calidad, nuevas tecnologías de la información y la comunicación, espacio físico, etc.

Medidas de demanda, dirigidas al nivel de actividad de las cooperativas - Facilitar el acceso a los mercados extranjeros y los mercados públicos. 
Dentro de las políticas duras o de fomento empresarial:medidas de oferta, dirigidas a mejorar la competitividad de las cooperativas, donde se encuadrarían las políticas fiscales de fomento, objeto de recientes investigaciones,que dan como resultado un ahorro fiscal de las cooperativas en su conjunto frente a las sociedades laborales de 1.002.284,65 miles de euros, en el período 1999-2009 -excluidos País Vasco y Navarra. Todo ello en once años supondría 91.116,78 miles de euros anuales como media de ahorro fiscal para el conjunto de las cooperativas en España (Herrero, 2012).

\section{INICIATIVAS EMPRESARIALES SOCIALES DE LA COMISIÓN EUROPEA DESDE 2011}

Durante más de dos décadas, las instituciones europeas -Parlamento, Comisión y el Comité Económico y Social- han reconocido la capacidad de la Economía Social para corregir importantes desequilibrios sociales y económicos y contribuir a lograr varios objetivos de interés general. Recientemente, el Parlamento Europeo ha aprobado un informe muy importante sobre la Economía Social y el CESE ha aprobado un dictamen sobre Distintos tipos de empresa, reconociendo el carácter específico y diferenciado de las empresas de economía social. Como resultado, incluso más que antes, los países miembros y la Comisión Europea deben asumir compromisos concretos para que la Secretaría de Economía no sólo sea un instrumento eficaz para alcanzar determinados objetivos de política pública de interés general -es decir, cooperativismo, mutualismo, asociacionismo y las iniciativas de interés general de la sociedad civil- sino también, en sí mismo un objetivo por derecho propio, indispensable para la consolidación de una sociedad desarrollada y los valores relacionados con el modelo social europeo. En este punto, las organizaciones representativas de la Economía Social tienen un papel importante que desempeñar, a través de la presentación de iniciativas y propuestas a las instituciones europeas, partidos políticos, sindicatos, universidades y otras organizaciones que representan a la sociedad civil (CESE, 2012). Las principales iniciativas son:

- Hacer frente a la crisis del estado del bienestar económico. Durante el periodo 2008-2012 la Economía Social ha mostrado una notable capacidad para afrontar las consecuencias negativas del actual ciclo de la depresión y hace una contribución significativa a las tres prin- 
cipales prioridades de la Estrategia Europa 2020: un crecimiento inteligente, sostenible e integrador.

- Impulsar la innovación en las empresas de Economía Social. La Economía Social es pionera en el lanzamiento de nuevos productos e iniciativas que luchan contra la exclusión social. Las empresas de Economía Social son más resistentes a la destrucción de empleo y la inseguridad. Debido a que tienen un modelo de gobierno más participativo y democrático, y los trabajadores están más comprometidos con la empresa como resultado de compartir la propiedad y el riesgo, las empresas que son autogestionadas por sus trabajadores están soportando la crisis económica mejor que otras. Se transmite el sistema de valor en solidaridad con la comunidad y el medio ambiente, la internalización de los costes sociales y la generación de externalidades positivas.

- Desarrollar un espacio integrado euromediterráneo, para convertirlo en un espacio de prosperidad y estabilidad. Para ello, todos los países ribereños del Mediterráneo necesitan consolidar estados democráticos fuertes, y sobre todo los países de la ribera sur necesitan ampliar el tejido productivo de su sociedad civil. En estos países, el crecimiento demográfico y otras razones estructurales obstaculizan que su crecimiento económico se traduzca en un mejor nivel de vida para la mayoría de la población, por lo que la región euro-mediterránea y la uE se ha convertido en una de las zonas geográficas con los mayores movimientos migratorios, tanto en términos de tamaño como de intensidad. Éstos se ven agravados por grandes grupos de población de América Latina, África Subsahariana y de países del sudeste asiático.

- Desarrollar un sistema universitario de enseñanza e investigación en Economía Social importante para el fomento de la cultura emprendedora y la democratización de la economía, a través de proyectos de formación que estimulen las iniciativas empresariales basadas en los valores que caracterizan la Economía Social.

- Transmisión de los valores identitarios de la Economía Social. La nueva Economía Social se está configurando en la Unión Europea como un polo de especial utilidad social en un sistema de economía plural, junto a un sector de la economía pública y un sector de la economía capitalista. 


\section{CONCLUSIONES}

Hemos alcanzado los objetivos propuestos que eran: explicar la función económica de la Economía Social, que justifica un tratamiento diferenciado de otras entidades de capital; analizar las distintas políticas públicas, que se pueden aplicar para estimular al sector y estudiar que iniciativas ya se están tomando a nivel de la Unión Europea al respecto.

Los poderes públicos -estatales, autonómicos y comunitarios- son cada vez más conscientes de la función económica de la Economía Social, y de su importancia y cada vez con mayor frecuencia, las empresas de Economía Social son tenidas en cuenta a la hora de diseñar las políticas públicas. Además el sector económico de la Economía Social está organizado y fuertemente institucionalizado, siendo reconocido como interlocutor válido por la Administración.

Es en esta época de crisis económica cuando las entidades de Economía Social se muestran más eficientes, resisten mejor y crean o mantienen el empleo. La crisis financiera que hemos vivido muestra cómo la economía capitalista no ha sabido, ni podido, manejar con eficiencia los mercados, ni ha conseguido el equilibrio económico. En cambio en el sector público, en general, y el sector de la economía social, en particular, se ha sabido tomar las riendas de las situación, mostrando gran capacidad y determinación a la hora de mantener y globalizar el bienestar.

Se vislumbra el sector económico de la Economía Social, las cooperativas y sociedades laborales fundamentalmente, como estratégico a la hora de combatir la crisis económica y el paro. Un sector que se reinventa día a día e innova continuamente.

La investigación en políticas públicas aplicadas a la Economía Social es la brújula para averiguar y graduar el estímulo o fomento adecuado, y para poder cuantificar el impacto real de estas medidas en la economía sectorial. Los fallos del mercado se intervienen a través de la política económica que: primero, estudia el problema y lo analiza, segundo, interviene y ejecuta y, en último lugar, vela por la máxima satisfacción y bienestar de la población. Intensificar la investigación en esta línea es la senda a seguir. 


\section{BIBLIOGRAFÍA}

ANHeIR, H. K. (2005): Nonprofit organizations. Theory, management, poli$c y$, New York, Rutledge.

Chaves, R. (2012): «Las Políticas Públicas y las Cooperativas». Ekonomiaz, 79, pp. 169-200.

Chaves, R. y J. L. Monzón (2003): «La Economía Social y la política económica», en Chaves, R. (ed.) (2003): Elementos de Economía Social. Teoría y realidad, Valencia, Universidad de Valencia.

- (2008): «Panorama de la investigación en Economía Social», Estudios de Economía Aplicada, vol.26, $\mathrm{n}^{\circ}$ 1, pp. 29 -55.

Chaves, R. y otros (1999): «La Economía Social y la Política económica», en JoRdán, J.M. (ed.) (1999): Política económica y actividad empresarial, Valencia, Tirant lo Blanc.

Comité Económico y Social Europeo (2012). «La Economía Social en la Unión Europea», Informe realizado por José Luis Monzón \& Rafael Chaves de CIRIEC, disponible en línea, [http://www.eesc.europa.eu/resources/docs/ qe-30-12-790-es-c.pdf], [Fecha de consulta 25.05.2013].

Cmaf. Comité Consultivo de la Comisión Europea de las Cooperativas, mutualidaDES, ASOCIACIONES Y FUNDACIONES (1999): L'économie sociale dans le dévelopement de l'UnionEuropéenne, Bruselas, Comisión Europea.

Defourny, J. y J. L. Monzón (1992a): The Third Sector. Cooperative, Mutual and Nonprofits Organizations,Bruxelles, De Boek.

- (1992b): Orígenes, contexto y funciones de un Tercer gran sector. Economía Social entre economía capitalista y economía pública, Valencia, CIRIEC- España Editorial.

Defourny, J. y otros (2009): The worldwide making of Social Economy. Innovations and changes, Leuven, Acco editorial.

Herrero, A. (2012): La fiscalidad como política de fomento de la economía social. El caso de la fiscalidad de las cooperativas en España, tesis doctoral, Valencia, Universitat de València.

NACIONES UnidAS(2007): «Las Cooperativas en el desarrollo social. Informe del Secretario General», documento en línea, disponible en [http://www.copac.coop/publications/un/a62154s.pdf]. [Fecha de consulta 15.05.2012]. Organización Internacional del Trabajo(2002): «Recomendación 193 de la OIT sobre la Promoción de Cooperativas» documento en línea [http:// www.aciamericas.coop/Recomendacion-193-de-la-OIT-sobre], [Fecha de consulta 18.03.2012] 
Salomon, L.M. (1999): America's Nonprofit Sector. A primer, New York, Foundation Center.

SAlOMON, L.M. y H.K. ANHEIR (1992): Insearch of the Nonprofit Sector: the question of definitions, Baltimore, WP, Johns Hopkins University.

- (1993): Insearch of the Nonprofit Sector: the problem of classifications, Baltimore, WP, Johns Hopkins University.

- (1996): The emerging nonprofit sector, an overview, Manchester, Manchester University Press.

Weisbrod, B.A. (1975): "Toward a Theory of the voluntary non profit in the Three Sector economy. Altruism, Morality and Economy Theory», Rusellsage, pp. 175-195.

- (1975): The voluntary Non-profit Sector, Massachusets. Lexington.

Weitzman, M. L. (1987): La economía de la participación, México, Fondo de Cultura Económica. 